\title{
Setting Control of Completely Recyclable Concrete with Slag and Aluminate Cements
}

\author{
by Mieke De Schepper, Jan De Maersschalck, Isabel Van Driessche, and Nele De Belie
}

A completely recyclable concrete $(C R C)$ is designed to have a chemical composition equivalent to the one of general raw materials for cement production. By doing so, this CRC can be used at the end of its service life in cement manufacturing without the need for ingredient adjustments. In one of the designed CRC compositions, blast-furnace slag cement (BFSC) was combined with calcium aluminate cement (CAC), which resulted in fast setting. In an attempt to control this fast setting, different retarders and/or the combination of lime and calcium sulfate were added to the system. The workability (slump and flow), setting time (ultrasonic transmission measurements and Vicat), strength development (compressive strength tests), and hydration behavior (isothermal calorimetry) were studied. It was found that the combined addition of lime and calcium sulfate results in a workable mixture that becomes even more workable if a retarder is also added to the system.

Keywords: calcium aluminate cement; completely recyclable concrete; portland clinker; setting control; workability.

\section{INTRODUCTION}

Construction and demolition waste represents 12 to $21 \%$ of the total waste generated in the European Union. ${ }^{1,2}$ To lower these amounts, many researchers are investigating the recycling opportunities within the building sector. One of the possible routes toward a more sustainable construction is the cradle-to-cradle $(\mathrm{C} 2 \mathrm{C})$ principle. ${ }^{3}$ In $\mathrm{C} 2 \mathrm{C}$ production, all material inputs and outputs are either seen as biological nutrients or technical resources. Biological nutrients can be composted or consumed, whereas technical resources can be recycled or reused without loss of quality. Applying this idea to the production of concrete, a completely recyclable concrete (CRC) was designed. ${ }^{4,5}$ After the demolition of a CRC construction, the material cycle is closed as the concrete rubble is given a second life as raw material for cement production, without the need for ingredient adjustments.

To enable the recycling of $\mathrm{CRC}$ within cement production, it is necessary that its chemical composition is similar to that of cement raw materials. ${ }^{6-9}$ As portland clinker consists of approximately two-thirds (62 to $68 \%$ ) calcium oxide $(\mathrm{CaO})$, limestone aggregate is an indispensable ingredient for CRC. Another major oxide in a clinker raw meal is silicon oxide $\left(\mathrm{SiO}_{2}, 17\right.$ to $\left.25 \%\right)$, which is found in sand and fly ash. The other components, aluminium oxide $\left(\mathrm{Al}_{2} \mathrm{O}_{3}, 2\right.$ to $\left.9 \%\right)$ and iron oxide $\left(\mathrm{Fe}_{2} \mathrm{O}_{3}, 0\right.$ to $\left.6 \%\right)$, are often present in the materials providing $\mathrm{CaO}$ and $\mathrm{SiO}_{2}$, but can also be provided by porphyry aggregates, copper slag or calcium aluminate cement $(\mathrm{CAC})$ to optimize the chemical composition of CRC.
The quality of the regenerated clinkers, obtained after burning of the $\mathrm{CRC}$ at $1450^{\circ} \mathrm{C}\left(2642^{\circ} \mathrm{F}\right)$, was studied by a mineralogical examination of their production process ${ }^{10}$ and quality ${ }^{4}$ and a hydration study on the regenerated cements. ${ }^{11}$ Both studies showed the feasibility of the CRC concept regarding the end product. Additionally, the sustainability of the CRC concept was verified ${ }^{12}$ and found to be dependent on the quality of the concrete and its clinker content. The environmental burden related to transport cannot be ignored. The main benefit of the CRC concept is related to the greenhouse gas emissions, which are strongly reduced due to the presence of $\mathrm{CO}_{2}$-free $\mathrm{CaO}$ in the cement paste. Finally, the choice for certain CRC raw materials can have consequences on the concrete quality. The use of fly ash will delay strength development and might affect the durability in a positive (improved chloride resistance) or negative (increased carbonation rate) way. ${ }^{13}$ The use of copper slag as an aggregate was found to have a limited effect on the concrete quality, especially from the low dosages that are required. ${ }^{13}$

Although the idea of CRC is noble, there are some practical issues concerning $\mathrm{CRC}$, one of them being the long time between the manufacturing of the concrete and the regeneration of the clinker. The evolution in cement manufacturing and, thus, clinker compositions over the next decades will be intense. However, the authors do not expect that the production of ordinary portland clinker will disappear completely. Additionally, the authors expect the composition of potentially new clinkers produced will still have a high $\mathrm{CaO}-\mathrm{SiO}_{2}-$ $\mathrm{Al}_{2} \mathrm{O}_{3}$ content, and by proper mixing, CRC can still be a partial substitution of the (primary) clinker raw meal. A well-considered tracking system will be required. It is of great importance that after some decades, the information regarding mixture design and location of the construction elements produced with CRC is still available. This should, however, be feasible for integrated cement and concrete producers. It is indeed seen that more and more companies want to implement the idea of "design for recycling" in their production process and they want to take back their own waste after its service life. At the moment, a project in the authors' research group, together with a prefab concrete

ACI Materials Journal, V. 113, No. 1, January-February 2016.

MS No. M-2014-305.R3, doi: 10.14359/51687979, received February 12, 2015, and reviewed under Institute publication policies. Copyright (C) 2016, American Concrete Institute. All rights reserved, including the making of copies unless permission is obtained from the copyright proprietors. Pertinent discussion including author's closure, if any, will be published ten months from this journal's date if the discussion is received within four months of the paper's print publication. 
manufacturer, is running whererin the setup of a labeling and tracing system is one of the research topics.

This paper presents a study of the deceleration of the hydration process of a CRC that combines both blastfurnace slag cement (BFSC) and calcium aluminate cement (CAC). When combining ordinary portland clinker (OPC, present in BFSC) with CAC, the reaction mechanism of both systems will interfere, which resulted in this case in fast setting and made the concrete unworkable within approximately 15 minutes. Furthermore, these mixtures are known to have a poor strength development in the absence of additives $^{14}$ and strength reduction at later ages due to delayed or secondary ettringite formation, ${ }^{15}$ which limits their use. The factors affecting the early strength development of these $\mathrm{OPC} / \mathrm{CAC}$ mixtures are the formation of ettringite, the main hydration product of these systems, ${ }^{15}$ and the delayed hydration of OPC. ${ }^{16,17}$ The importance of the ettringite formation in such systems is explained in detail by Amathieu et al. ${ }^{14}$ The formation of ettringite from $\mathrm{Al}^{3+}, \mathrm{SO}_{4}{ }^{2-}$, and $\mathrm{Ca}^{2+}$ ions in the solution dominates the early hydration reactions. It is furthermore known that the rapid hydration of the aluminate phase in OPC is controlled by adding calcium sulfate. When combining CAC and $\mathrm{OPC}$, the $\mathrm{SO}_{4}{ }^{2-}$ ions will react also with $\mathrm{Al}^{3+}$ ions from $\mathrm{CAC}$ and, subsequently, the retardation mechanism of $\mathrm{C}_{3} \mathrm{~A}$ (calcium aluminate, $3 \mathrm{CaO} \cdot \mathrm{Al}_{2} \mathrm{O}_{3}$ ) by adding calcium sulfate in the OPC system is reversed.

To slow down the hydration, different retarders were first tested. Additionally, the effect of lime and calcium sulfate addition was investigated because it was found in literature ${ }^{14}$ to affect the setting times of mixtures combining CAC/OPC. Finally, the combination of both methods was tried out. The experimental work focused on achieving a good workability (slump and flow) and setting time (ultrasonic transmission measurements and Vicat), but also the strength development (compressive strength tests) and hydration behavior (isothermal calorimetry) were verified.

\section{RESEARCH SIGNIFICANCE}

Much research toward a more sustainable cement and concrete industry is ongoing. The approach of completely recyclable concrete (CRC), based on the $\mathrm{C} 2 \mathrm{C}$ concept, is relatively new. The feasibility and potential environmental benefits of this concept were already proven; however, when developing this new concrete, some difficulties related to concrete technology were encountered. One of them being the fast setting of a concrete combining calcium aluminate cement (CAC) with blast-furnace slag cement (BFSC). This paper presents the results of a study on the deceleration of the reaction of the binder system focusing on obtaining a good workability and setting time.

\section{EXPERIMENTAL PROCEDURE}

\section{Mixture design}

A CRC was designed to be used as the single ingredient for a cement raw meal. ${ }^{4}$ Within this CRC, BFSC $(85 \%)$ was combined with CAC $(15 \%)$, which resulted in fast setting. Different additions were studied to slow down the fast hydration of the studied CRC. To minimize the material cost and effort, the tests were carried out on equivalent mortar mixtures. The compositions of these mortars were calculated according to the Mortier de Béton Equivalent (MBE) method. ${ }^{18}$ To obtain a workability behavior of the MBE mortar identical to that of the corresponding concrete mixture, the total amount of aggregates was replaced by an amount of sand, $\Delta f_{\text {sand }}$, in $\mathrm{lb}(\mathrm{kg})$

$$
\Delta f_{\text {sand }}=\frac{f_{\text {agg }, 1} \cdot s_{\text {agg }, 1}+f_{\text {agg }, 2} \cdot s_{\text {agg }, 2}}{s_{\text {sand }}}
$$

where $f_{\text {agg, } x}(\mathrm{lb}[\mathrm{kg}])$ the mass of aggregate $x$; and $s_{a g g, x}$ (in. $.^{2} / \mathrm{lb}\left[\mathrm{m}^{2} / \mathrm{kg}\right]$ ) and $s_{\text {sand }}\left(\right.$ in. ${ }^{2} / \mathrm{lb}\left[\mathrm{m}^{2} / \mathrm{kg}\right]$ ) are the specific surface areas of aggregate $x$ and sand, respectively. The amount of water was also corrected with $\Delta f_{\text {water }}$, in $\mathrm{lb}(\mathrm{kg})$

$$
\Delta f_{\text {water }}=-f_{\text {agg }, 1} \cdot A_{\text {agg, } 1}-f_{\text {agg, }, 2} \cdot A_{\text {agg }, 2}+\Delta f_{\text {sand }} \cdot A_{\text {sand }}
$$

where $A_{\text {agg, } x}$ and $A_{\text {sand }}$ are the absorption coefficient of aggregate $x$ and sand, respectively. In Table 1, the composition of the MBE mortar is presented together with the original concrete composition. In addition to the $\mathrm{CRC}$ mixture, two reference mixtures with water-cement ratios $(w / c)$ of 0.50 and 0.45 were tested: $\mathrm{T}(0.50)$ and $\mathrm{T}(0.45)$. The chemical compositions of the cements and fly ash used in this stud can be found in Table 2 .

In a first attempt to slow down the hydration process, three types of retarders were added to the system, namely, a commercial retarder on the basis of gluconate (CR; $4.53 \mathrm{~mL} / \mathrm{lb}$ binder [10 $\mathrm{mL} / \mathrm{kg}$ binder]; liquid), sucrose (S; $0.10 \mathrm{wt} \%$ of the binders; powder), and citric acid (CA; 0.10 $\mathrm{wt} \%$ of the binders; powder). It was found that lime and calcium sulfate have an influence on the setting of OPC/CAC hydration. ${ }^{14}$ Concurrently, the combined addition of slaked lime $\left(\mathrm{Ca}(\mathrm{OH})_{2} ; 4 \mathrm{wt} \%\right.$ of the binders $)$ and calcium sulfate $\left(2 / 3 \mathrm{CaSO}_{4} \cdot 1 / 2 \mathrm{H}_{2} \mathrm{O}\right.$ and $1 / 3 \mathrm{CaSO}_{4} ; 6 \mathrm{wt} \%$ of the binders $)$ was tested (LCS). Initially, three mixtures of lime and calcium sulfate were tested with $\mathrm{CaO} / \mathrm{CaSO}_{4}$ ratios of $2.7 / 4,3.3 / 5$, and $4 / 6$. As the latter gave the best results regarding slump and flow, it was the only one used for further testing. Finally, both methods were combined and each type of retarder was combined with the lime and calcium sulfate addition (LCS/CR, LCS/S, and LCS/CA). All mixtures were tested for their workability (by slump and flow tests) and their hydration heat (by isothermal calorimetry). After these first tests, the setting times (by ultrasonic transmission and Vicat needle measurements) and the strength development were studied for three CRC mixtures, namely, those with the commercial retarder (CR), the lime and calcium sulfate addition (LCS), and the combination of both (LCS/CR).

\section{Methods}

To evaluate the workability of the fresh MBE mortars, their slump and flow was determined. The procedure to determine the flow is described in NBN EN 413-2. ${ }^{19}$ The slump was measured with a mini cone, ${ }^{18}$ which is similar to the Abrams cone for slump measurements of concrete (NBN EN $\left.12350-2^{20}\right)$. 
Table 1-Overview of MBE mortar compositions together with their original concrete compositions, $\mathrm{lb} / \mathrm{yd}^{3}\left(\mathrm{~kg} / \mathrm{m}^{3}\right)$

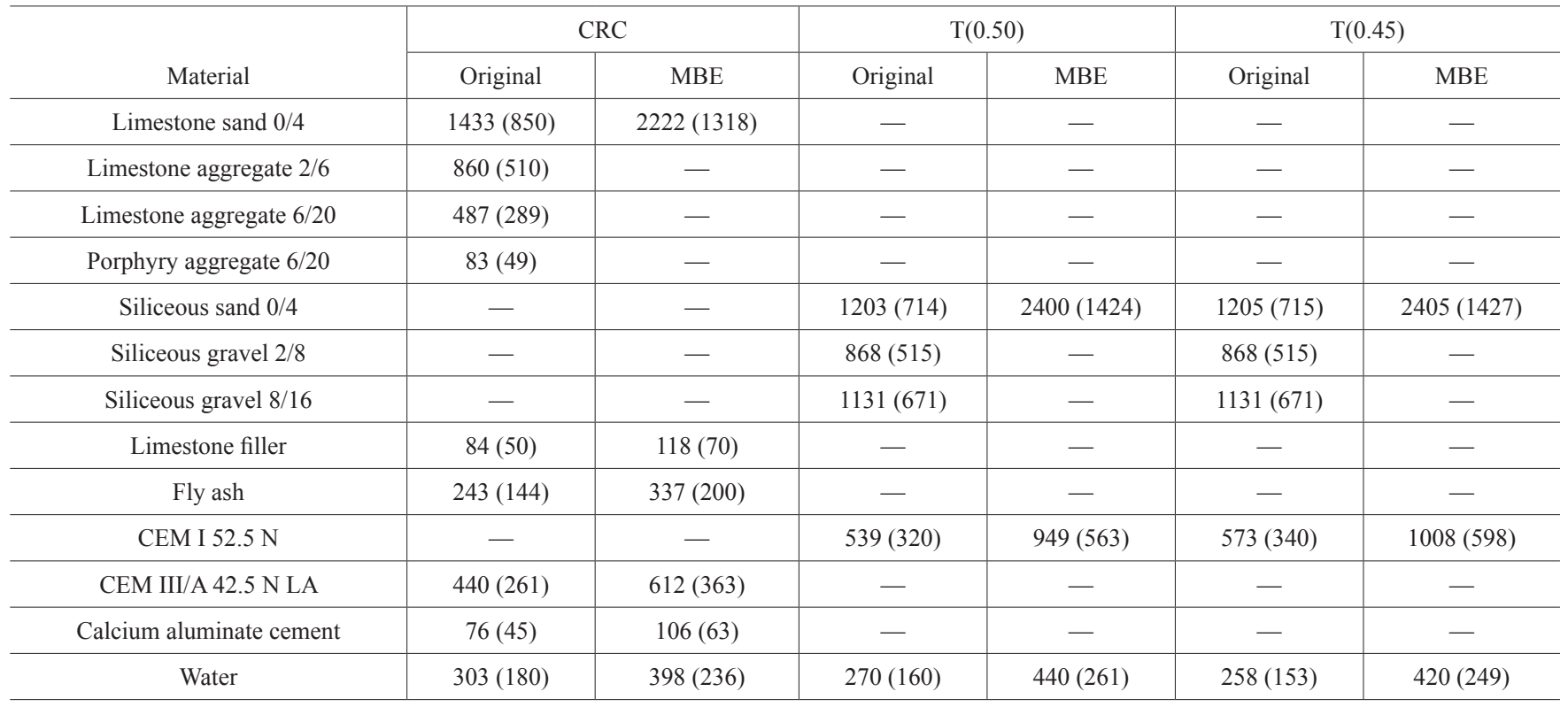

Table 2-Overview of chemical compositions of cements and fly ash used in present study, wt $\%$

\begin{tabular}{c|c|c|c|c}
\hline Material & $\begin{array}{c}\text { CEM I } \\
52.5 \mathrm{~N}\end{array}$ & $\begin{array}{c}\text { CEM III/A 42.5 } \\
\text { N LA }\end{array}$ & $\begin{array}{c}\text { Calcium aluminate } \\
\text { cement }\end{array}$ & Fly ash \\
\hline $\mathrm{CaO}$ & 63.4 & 52.7 & 39.9 & 4.82 \\
\hline $\mathrm{SiO}_{2}$ & 18.9 & 28.0 & 2.80 & 50.5 \\
\hline $\mathrm{Al}_{2} \mathrm{O}_{3}$ & 5.77 & 8.92 & 39.4 & 29.1 \\
\hline $\mathrm{Fe}_{2} \mathrm{O}_{3}$ & 4.31 & 2.67 & 17.5 & 4.59 \\
\hline $\mathrm{MgO}$ & 0.89 & 4.06 & 0.42 & 0.95 \\
\hline $\mathrm{K}_{2} \mathrm{O}$ & 0.73 & 0.50 & - & 1.37 \\
\hline $\mathrm{Na}_{2} \mathrm{O}$ & 0.47 & 0.36 & 0.06 & 0.39 \\
\hline $\mathrm{P}_{2} \mathrm{O}_{5}$ & - & - & - & 1.13 \\
\hline $\mathrm{SO}_{3}$ & - & 3.05 & - & 0.82 \\
\hline $\mathrm{Cl}^{-}$ & - & 0.05 & - & $<0.001$ \\
\hline \multicolumn{5}{c}{ Loss on ignition } \\
\hline
\end{tabular}

Ultrasonic p-wave transmission measurements were performed on concrete $(\mathrm{T}(0.45), \mathrm{T}(0.50)$, and $\mathrm{CRC}$ with LCS) or MBE mortar (CRC with CR or LCS/CR) samples using the FreshCon system developed at the University of Stuttgart. ${ }^{21}$ More details on the used test setup and conditions can be found elsewhere. ${ }^{22,23}$ The FreshCon system also measures the frequency content of the received ultrasonic signals, but in this study, the velocity and energy curves were considered for determining the initial and final setting of the mixtures. The initial setting time using the velocity curves was determined by its inflection point. ${ }^{22,24}$ The final setting time was set as the point at which the derivative of the velocity curve decreased to $20 \%$ of its maximum value. ${ }^{22}$ For deducting the initial setting times from the energy curves, the thresholds $E / E_{\text {ref }}=0.01$ and 0.02 were used for concrete and mortar, respectively. ${ }^{22}$ Likewise, the values $E / E_{\text {ref }}=0.07$ and 0.13 were used to determine the final setting times for concrete and mortar samples, respectively. For the CRC mixtures, the setting behavior was also monitored more traditionally using the Vicat needle, for which CRC cement pastes were produced with a standard consistence (NBN EN 196-325).

The hydration behavior of cement pastes was investigated using an isothermal heat conduction calorimeter at $68^{\circ} \mathrm{F}$ $\left(20^{\circ} \mathrm{C}\right)$. Each paste contained $8.88 \times 10^{-3} \mathrm{lb}(4 \mathrm{~g})$ water and $2.20 \times 10^{-2} \mathrm{lb}(10 \mathrm{~g})$ binder (BFSC/CAC/fly ash in the case of CRC; CEM I $52.5 \mathrm{~N}$ in the cases of $\mathrm{T}(0.45)$ and $\mathrm{T}(0.50)$ ) and the studied retarder. To avoid significant temperature differences between the paste and the isothermal environment, the components were kept at a temperature close to the measurement temperature before mixing. The components were mixed manually. The hydration heat was measured over 7 days.

The development of the compressive strength was studied by performing compressive strength tests at the age of 2, 7, and 28 days. For each age, six MBE mortar samples $(1.58 \mathrm{x}$ $1.58 \times 6.30$ in. $^{3}$ [ $\left.40 \times 40 \times 160 \mathrm{~mm}^{3}\right]$ ) were tested according to NBN EN 196-1. ${ }^{26}$

\section{EXPERIMENTAL RESULTS}

\section{Workability}

The workability of the mixtures was determined by slump and flow tests 20 minutes after mixing; the results are presented in Table 3. First, three retarders were used separately to slow down the fast setting of the CRC mixtures: a commercial retarder, sucrose, and citric acid. As seen in Table 3, no slump or flow was measured. As it was found that lime and calcium sulfate have an influence on the fast setting of mixtures with OPC and CAC, this effect was also tested. A slump and flow could be measured, and the results improved even more when combining a retarder with the addition of lime and calcium sulfate. 


\section{Setting times}

The setting times of the reference mixtures and the CRC mixtures with the commercial retarder, the combined lime and calcium sulfate addition, and the combination of both, are presented in Table 4. Regarding the results for the CRC mixture with lime and calcium sulfate, it was not possible to deduct the setting times from the velocity curves, as no inflection point was obtained. For the energy curves, it was not possible to deduct the final setting time for the CRC

Table 3-Slump and flow measured 20 minutes*

\begin{tabular}{c|c|c|c|c}
\hline \multirow{2}{*}{ Mixture } & \multicolumn{2}{|c|}{ Slump } & \multicolumn{2}{c}{ Flow } \\
\cline { 2 - 5 } & in. & $\mathrm{mm}$ & in. & $\mathrm{mm}$ \\
\hline $\mathrm{T}(0.45)$ & 0.39 & 10 & 5.41 & 138 \\
\hline $\mathrm{T}(0.50)$ & 0.47 & 12 & 5.51 & 140 \\
\hline CRC-CR & 0.00 & 0 & 4.43 & 113 \\
\hline CRC-S & 0.00 & 0 & 3.94 & 100 \\
\hline CRC-CA & 0.00 & 0 & 4.04 & 103 \\
\hline CRC-LCS & 1.18 & 30 & 6.00 & 153 \\
\hline CRC-LCS/CR & 5.31 & 135 & 11.52 & 293 \\
\hline CRC-LCS/S & 5.71 & 145 & 11.81 & 300 \\
\hline CRC-LCS/CA & 5.31 & 135 & 11.81 & 300 \\
\hline
\end{tabular}

*After mixing of reference mortars $(\mathrm{T}(0.45)$ and $\mathrm{T}(0.50))$ and $\mathrm{CRC}$ mortar with retarder (CR, S or CA), lime and calcium sulfate addition (LCS), or combination of both (LCS/CR, LCS/S, LCS/CA). mixture with the commercial retarder, as the threshold of 0.13 was not reached within the first 48 hours. Previous research ${ }^{22}$ showed that the energy curves are preferred over the velocity curves to determine setting times if admixtures are used. The criteria for the energy ratio still give a good indication of the initial and final setting times on the mortar mixtures, although more variation is noticed. The shape of the velocity curves is sometimes significantly altered and, therefore, characteristic points such as the inflection point are not discussed. For this reason, only the energy curves are presented in this paper (refer to Fig. 1).

In Table 4, it is seen that there is a high variability for the results obtained by the different techniques. The setting times deducted from the velocity curves did not confirm the expectations from the workability and hydration tests. Looking at the energy curves, the final setting times are significantly longer compared to the ones from the velocity curves. The difference in the initial setting times is, however, limited. In Fig. 1, it is seen that for all CRC mixtures, the initial rise of the energy ratios is much stronger than those of the reference mixtures. For the CRC concrete mixture with lime and calcium sulfate addition (LCS), it is seen that eventually it reaches the same energy ratio as the reference mixtures.

As admixtures and supplementary cementitious materials (SCMs) are known to influence the velocity and energy curves from ultrasonic transmission measurements, ${ }^{22,23,27,28}$

Table 4-Overview of setting times, hours

\begin{tabular}{c|c|c|c|c|c|c}
\hline \multirow{2}{*}{ Mixture } & \multicolumn{2}{|c|}{ p-wave velocity } & \multicolumn{2}{c}{ p-wave energy } & \multicolumn{2}{c}{ Vicat } \\
\cline { 2 - 6 } & Initial setting & Final setting & Initial setting & Final setting & Initial setting & Final setting \\
\hline $\mathrm{T}(0.45)$ & $3.55(\mathrm{c})$ & $5.43(\mathrm{c})$ & $5.44(\mathrm{c})$ & $10.27(\mathrm{c})$ & - & - \\
\hline $\mathrm{T}(0.50)$ & $3.22(\mathrm{c})$ & $4.56(\mathrm{c})$ & $5.38(\mathrm{c})$ & $12.97(\mathrm{c})$ & - & 1.30 \\
\hline CRC-CR & $0.70(\mathrm{~m})$ & $1.15(\mathrm{~m})$ & $0.70(\mathrm{~m})$ & $\mathrm{NA}$ & 1.50 \\
\hline CRC-LCS & $\mathrm{NA}$ & $\mathrm{NA}$ & $2.95(\mathrm{c})$ & $8.70(\mathrm{c})$ & 4.40 & 7.58 \\
\hline CRC-LCS/CR & $0.18(\mathrm{~m})$ & $0.98(\mathrm{~m})$ & $1.08(\mathrm{~m})$ & $13.90(\mathrm{~m})$ & 6.83 & 10.33 \\
\hline
\end{tabular}

"As determined from p-wave velocity or energy curve from ultrasonic transmission measurements on concrete (c) or mortar (m) samples or by using Vicat needle on pastes. Reference mixtures $\mathrm{T}(0.45)$ and $\mathrm{T}(0.50)$ were tested besides CRC mixtures with commercial retarder (CR), lime and calcium sulfate addition (LCS), or combination of both (LCS/CR).
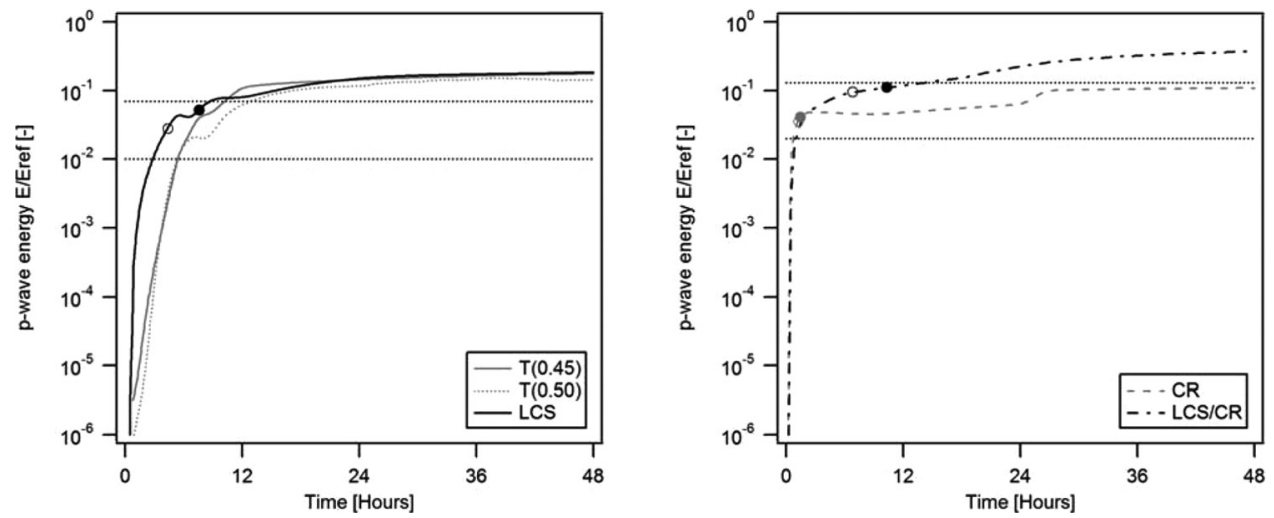

Fig. 1-Ultrasonic p-wave energy curves for concrete (left) and mortar (right) mixtures. Reference mixtures T(0.45) and $T(0.50)$ were tested besides CRC mixtures with commercial retarder (CR), lime and calcium sulfate addition (LCS), or combination of both (LCS/CR). Initial and final setting times obtained by Vicat are presented by open and closed bullets, respectively. Horizontal lines present energy ratio thresholds for determining initial (lowest) and final (highest) set for mortar and concrete mixtures. 

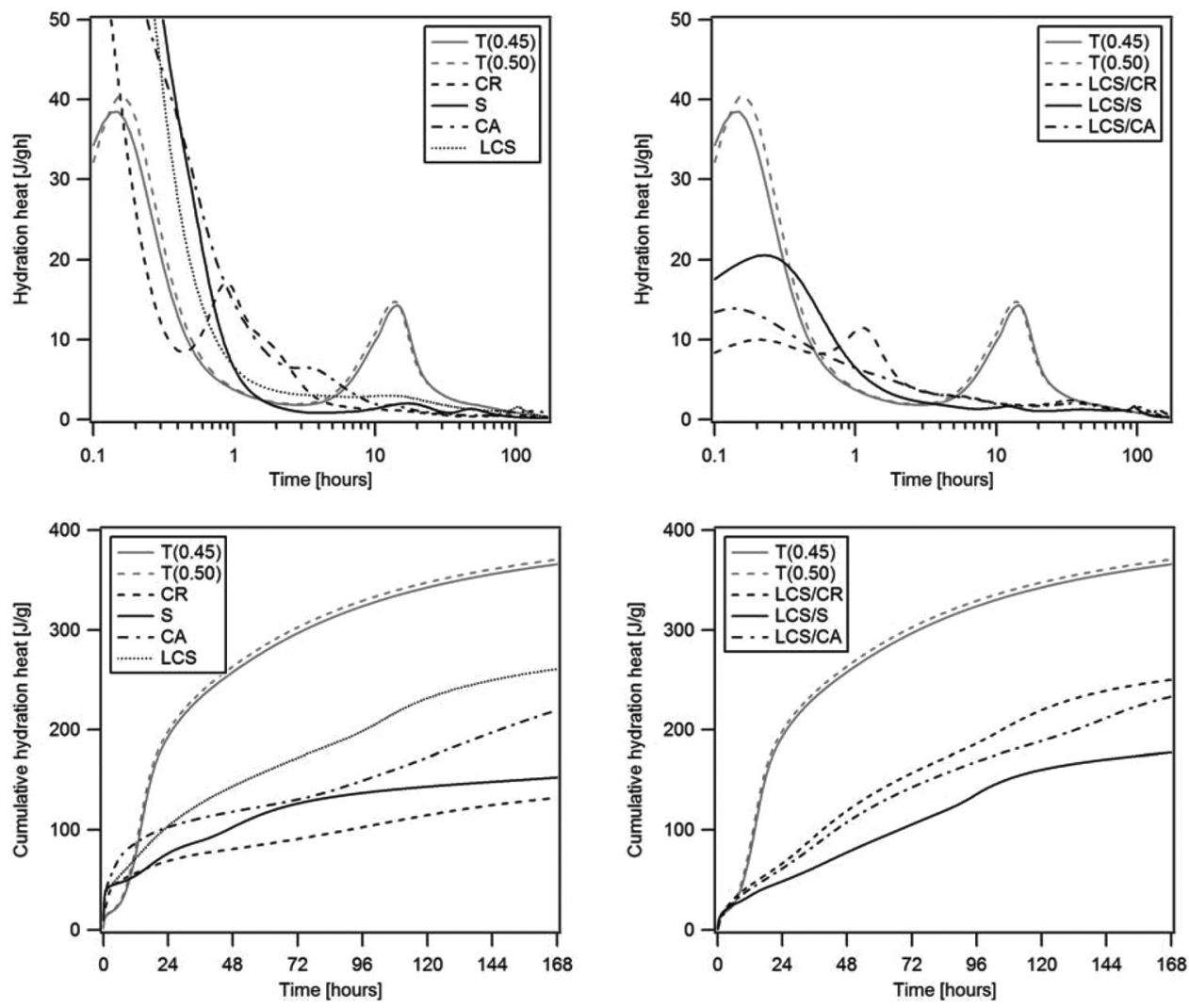

Fig. 2-Hydration heat and cumulative hydration heat of reference mixtures $T(0.45)$ and $T(0.50)$ and CRC mixtures with retarder (commercial retarder [CR], sucrose [S], or citric acid [CA]), lime and calcium sulfate addition (LCS), or combination of both ( $L C S / C R, L C S / S$, and $L C S / C A)$.

the setting times were determined more traditionally using a Vicat needle. For these tests the expected improvement of the setting times can be seen for the lime and calcium sulfate addition, with or without the commercial retarder. When projecting the results of the Vicat measurements on the energy curves, it is seen that the thresholds for the initial and final setting times as proposed by Robeyst ${ }^{22}$ and Robeyst et al. ${ }^{23,28}$ do not seem applicable for the study's CRC mixture with CAC and BFSC. It seems, however, impossible to propose new thresholds, as the energy ratios corresponding with initial and final set have a high variability.

Although the presence of admixtures and SCMs in the CRC mixtures will probably have their effect on the velocity and energy curves, there might also be another explanation for the differences between the ultrasonic transmission measurements and the Vicat needle. In CAC/OPC mixtures, ettringite is formed during the first hours of cement hydration in the shape of stubby crystals or thin needles. ${ }^{14}$ Depending on the $w / c$ and the chemical composition of the system, ettringite has no or a very small influence on the stiffening of the cement paste. ${ }^{29}$ Nevertheless, in contrast to the setting behavior, the p-wave velocity and energy are strongly affected by the formation of ettringite. The crystals do not create bonds between the cement particles at early hydration times, but they fill pore space that was previously occupied by water and, thus, the velocity will increase. As the formation of ettringite is limited in OPC mixtures, the influence on the velocity will also be minimal. In a CAC/ OPC mixture with lime and calcium sulfate added, much more ettringite will be formed and this effect is possibly seen in the ultrasonic transmission measurements.

\section{Hydration heat}

The left graphs of Fig. 2 show the (cumulative) heat evolution of the CRC mixtures with a retarder or a lime and calcium sulfate addition. It is seen that during the first hour, a lot of heat is produced, but after the first hours, all reactions slowed down. Also, the characteristic peak from alite hydration around 10 hours is missing from all CRC curves. It should be mentioned that the intense heat liberation upon mixing might have influenced the results during the first hours, and the isothermal conditions are not guaranteed.

The hydration heat during the first hours seems to be better controlled for the CRC mixtures that combine the addition of a retarder with lime and calcium sulfate addition (refer to the right-hand graphs of Fig. 2). For the first 10 hours, the cumulative hydration heat of the CRC mixtures is close to the curves of the reference mixtures. However, after this period, the alite hydration starts for the reference mixtures, and this process seems to be slowed down significantly for the $\mathrm{CRC}$ mixtures.

The mixtures containing the commercial retarder (with or without lime and calcium sulfate addition) show a peak after approximately 1 hour of hydration, which is missing for the mixtures with sucrose and citric acid. It is possible that this peak results from the hydration of the aluminate phases of the BFSC and/or CAC. One could also think of early alite hydration, but this would be rather fast and only a very small 
amount of the total alite content would have been hydrated considering the small contribution to the cumulative heat production. In the end, the origin of this peak was not examined, as it was not within the scope of this study.

\section{Strength development}

Besides workability, which is related to the setting time of concrete mixtures, the compressive strength is also an important parameter for practical applications. Looking at the results of the isothermal calorimetry, it is seen that after 7 days, the total hydration heat for the CRC mixtures is significantly lower than the reference mixtures. Although the considered $\mathrm{BFSC} / \mathrm{CAC}$ binder system is completely different from a single binder system, it was nonetheless interesting to check the strength development toward practical applications because hydration heat is known to be related to the hydration degree of cement pastes, mortars, or concrete. The results of the compressive strength tests on 2,7 , and 28 days of the CRC mixture with a commercial retarder, the combined lime and calcium sulfate addition, or a combination of both, are presented in Fig. 3 .

From the compressive strength tests it can be concluded that, after 2 days, the strength for all CRC mixtures is significantly lower compared to that of the reference mixtures. Indeed, retarders do not only delay the early hydration of the aluminate phases (and thus setting), but are also known as strong retarders for alite hydration. For the CRC mixture with the commercial retarder, the compressive strength at later ages -7 and 28 days - is inferior compared to the reference mixtures. The results at 7 and 28 days for the CRC mixtures with lime and calcium sulfate, with or without commercial retarder, are both comparable with the reference mixtures, showing that the addition of lime and calcium sulfate significantly improves the strength development of the CRC mixture.

\section{SUMMARY}

The aim of this study was to produce a CRC combining $\mathrm{CAC}$ and BFSC with an appropriate workability and setting time, comparable to the one of OPC concrete. For this purpose, different retarders based on gluconate, sucrose, or citric acid were added to the mixtures, but without success. In the literature, it was found that the addition of calcium sulfate, especially in combination with lime, affects the setting of such CAC/OPC mixtures. The beneficial effects of lime and calcium sulfate addition on the workability were proven by slump and flow tests. The results improved even more when the lime and calcium sulfate addition was combined with a retarder. Notwithstanding these good results, the effect was not observed by the ultrasonic transmission measurements using the FreshCon system, possibly due to the formation of significant amounts of ettringite affecting the p-wave velocity and energy curves. However, the latter has no or a very small influence on the stiffening of the cement paste at early age. On the other hand, when using the Vicat needle to study the setting times of the mixtures, the advantageous effect on the setting times was observed.

Although the desired workability was obtained, the cumulative hydration heat of all CRC mixtures measured during

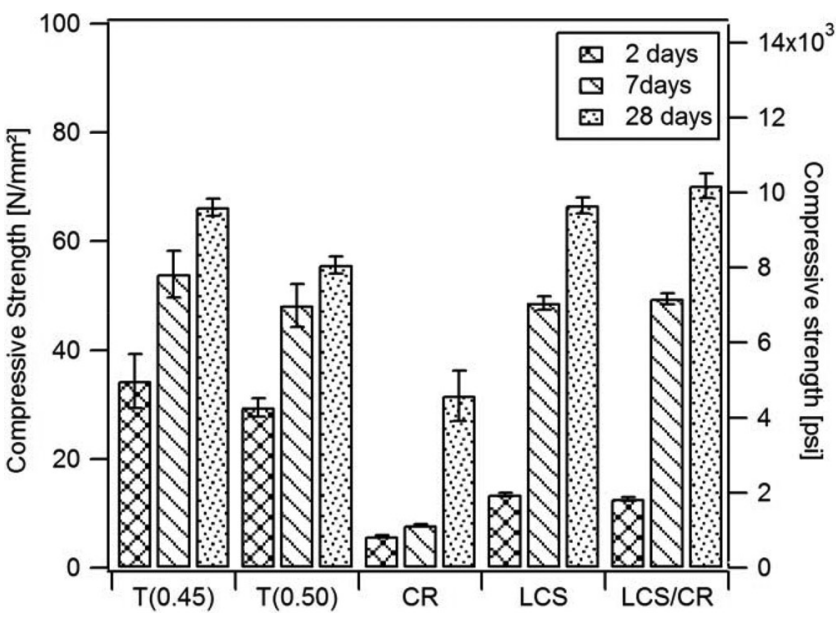

Fig. 3-Strength development of reference mixtures $T(0.45)$ and $T(0.50)$ and $C R C$ mixtures with commercial retarder $(C R)$, lime and calcium sulfate addition (LCS), or combination of both (LCS/CR).

the first 7 days of hydration was significantly lower compared to the reference mixtures. The latter is related to the complex binder system containing a low-heat cement (BFSC) and two binder types (BFSC and CAC) which influence each other's reactions. Nonetheless, because the strength development is related to the hydration heat, the compressive strength was checked after 2,7 , and 28 days of hydration. The early strength ( 2 days) was significantly lower for the mixtures with lime and calcium sulfate addition, but after 7 and 28 days, the strength development was comparable to the one of the reference mixtures.

Despite the fact that producing a CRC combining BFSC and $\mathrm{CAC}$ with an appropriate workability was a success, the authors cannot ignore the fact that the optimal combination of calcium sulfate, lime, and maybe also a retarder should be selected over and over again. The latter will make the entire concept of CRC, which is designed for reincarnation in cement production, even more complex. For this reason, it was concluded that it is wiser to use such fastsetting mixtures only when fast setting is actually one of the requirements for application. Indeed, OPC/CAC mixtures are often used for flooring installations, rapid wall construction, and concrete repair (sealing of leaks and road pavement repair) due to their unique properties: adjustable setting time, rapid hardening and drying, dimensional stability, good adhesion and compatibility with existing concrete, and corrosion resistance. ${ }^{14,16,17}$ It should also be mentioned that further research on the long-term behavior of such mixtures is required. Special attention should be paid to the potential occurrence of conversion reactions that are known to take place in CAC mixtures. The conversion rate of the first hydrates (metastable phases) to the final hydrates is dependent on temperature, moisture state, and possibly other variables such as $w / c$.

\section{CONCLUSIONS}

This paper presents the results of a search toward the delay of the setting time of a completely recyclable concrete (CRC) that combines blast-furnace slag cement and calcium 
aluminate cement. It was found that the workability cannot be improved if a retarder (commercial retarder, sucrose, or citric acid) is added, but the addition of lime and calcium sulfate results in a workable mixture that becomes even more workable if a retarder is also added. The improvement of the workability was also deducted from the setting times determined with the Vicat needle. The improvement could not be detected by the ultrasonic transmission measurements. Although the total hydration heat after 7 days for all CRC mixtures was significantly lower compared to the reference mixtures, the compressive strength after 7 and 28 days of the CRC mixtures with the addition of lime and calcium sulfate, with or without retarder, was sufficient for practical applications.

\section{AUTHOR BIOS}

Mieke De Schepper is Researcher at the Magnel Laboratory for Concrete Research at Ghent University, Ghent, Belgium, where she received her $P h D$ in 2014. Her research interests include the use of waste materials in concrete, portland cement chemistry, and sustainability of concrete.

Jan De Maersschalck was a Master Student at the Magnel Laboratory for Concrete Research at Ghent University, where he received his master's degree in 2011.

Isabel Van Driessche is a Professor at Ghent University. She is Head of the Department or Inorganic and Physical Chemistry and leads the research group, SCRiPTS, whose research includes solid-state chemistry related to the synthesis, and properties and applications of inorganic and ceramic materials, both as bulk and thin films.

Nele De Belie is a Professor of durability of cement-bound materials at Ghent University. She is Technical Director of the Magnel Laboratory for Concrete Research, and leads the research group, Concrete and Environment, whose research includes cement and concrete related to durability and sustainability.

\section{ACKNOWLEDGMENTS}

Financial support from the Institute for the Promotion of Innovation through Science and Technology in Flanders (IWT-Vlaanderen) and of the Research Foundation Flanders (FWO project G087510N) is gratefully acknowledged.

\section{REFERENCES}

1. De Belie, N., and Robeyst, N., "Recycling of Construction Materials," Environment-Conscious Construction Materials and Systems-RILEM Report No. 37, N. Kashino, D. Van Gemert, and K. Imamoto, eds., RILEM Publications S.A.R.L., Bagneux, France, 2007, pp. 11-23.

2. Fischer, C., and Werge, M., "EU as a Recycling Society," European Topic Centre on Resource Waste Management, Working paper 2/2009, European Topic Centre on Sustainable Consumption and Production, Copenhagen, Denmark, 2009, 73 pp.

3. McDonough, W., and Braungart, M., Cradle to Cradle: Remaking the Way We Make Things, first edition, North Point Press, New York, 2002, $195 \mathrm{pp}$.

4. De Schepper, M.; De Buysser, K.; Van Driessche, I.; and De Belie, N., "The Regeneration of Cement Out of Completely Recyclable Concrete: Clinker Production Evaluation," Construction and Building Materials, V. 38, 2013, pp. 1001-1009. doi: 10.1016/j.conbuildmat.2012.09.061

5. Tamura, M.; Noguchi, T.; and Tomosawa, F., "Cementitious WasteFree-Type Completely Recyclable Concrete," RILEM International Symposium on Environment-Conscious Materials and Systems for Sustainable Development, N. Kashino and Y. Ohama, eds., RILEM, 2004, pp. 61-71.

6. BBG, Betontechnologie, De Belgische BetonGroepering, 2006.

7. Huntzinger, D. N., and Eatmon, T. D., "A Life-Cycle Assessment of Portland Cement Manufacturing: Comparing the Traditional Process with Alternative Technologies," Journal of Cleaner Production, V. 17, No. 7, 2009, pp. 668-675. doi: 10.1016/j.jclepro.2008.04.007
8. Taerwe, L., and De Schutter, G., "Betontechnologie (Syllabus Concrete Technology)," Ghent University, Ghent, Belgium, 2006.

9. Taylor, H. F. W., Cement Chemistry, second edition, Thomas Telford Publishing, London, UK, 1997, $480 \mathrm{pp}$

10. Snellings, R.; De Schepper, M.; De Buysser, K.; Van Driessche, I.; and Belie, N., "Clinkering Reactions during Firing of Recyclable Concrete," Journal of the American Ceramic Society, V. 95, No. 5, 2012, pp. 17411749. doi: 10.1111/j.1551-2916.2012.05168.x

11. De Schepper, M.; Snellings, R.; De Buysser, K.; Van Driessche, I.; and De Belie, N., "The Hydration of Cement Regenerated from Completely Recyclable Concrete," Construction and Building Materials, V. 60, 2014, pp. 33-41. doi: 10.1016/j.conbuildmat.2014.02.067

12. De Schepper, M.; Van den Heede, P.; Van Driessche, I.; and De Belie, N., "Life Cycle Assessment of Completely Recyclable Concrete," Materials (Basel), V. 7, No. 8, 2014, pp. 6010-6027. doi: 10.3390/ ma7086010

13. De Schepper, M., "Completely Recyclable Concrete for a More Environment-Friendly Construction (Volledig recycleerbaar beton voor een meer milieuvriendelijke bouwsector)," PhD dissertation, Ghent University, Ghent, Belgium, 2014, 234 pp.

14. Amathieu, L.; Bier, T. A.; and Scrivener, K. L., "Mechanisms of Set Acceleration of Portland Cement through CAC Addition," International Conference on Calcium Aluminate Cements (CAC), R. J. Mangabhai and F. P. Glasser, eds., Edinburgh, Scotland, 2001, pp. 303-317.

15. Gawlicki, M.; Nocuń-Wczelik, W.; and Bąk, Ł., "Calorimetry in the Studies of Cement Hydration," Journal of Thermal Analysis and Calorimetry, V. 100, No. 2, 2010, pp. 571-576. doi: 10.1007/s10973-009-0158-5

16. Gu, P.; Beaudoin, J. J.; Quinn, E. G.; and Myers, R. E., "Early Strength Development and Hydration of Ordinary Portland Cement/Calcium Aluminate Cement Pastes," Advanced Cement Based Materials, V. 6, No. 2, 1997, pp. 53-58. doi: 10.1016/S1065-7355(97)00008-4

17. Gu, P.; Fu, Y.; and Beaudoin, J. J., "A Study of the Hydration and Setting Behaviour of OPC-HAC Pastes," Cement and Concrete Research, V. 24, No. 4, 1994, pp. 682-694. doi: 10.1016/0008-8846(94)90192-9

18. Schwartzentruber, A., and Chatherine, C., "La méthode du mortier de béton équivalent (MBE) - un nouvel outel d'aide à la formulation des bétons adjuvantés," Matériaux et Construction, V. 33, 2000, pp. 475-482.

19. NBN EN 413-2, "Masonry Cement—Part 2 : Test Methods," Bureau for Standardisation, Brussels, Belgium, 2005, $20 \mathrm{pp}$.

20. NBN EN 12350-2, "Testing Fresh Concrete-Part 2: Slump-Test," Bureau for Standardisation, Brussels, Belgium, 1999, 8 pp.

21. Reinhardt, H. W., and Grosse, C. U., "Continuous Monitoring of Setting and Hardening of Mortar and Concrete," Construction and Building Materials, V. 18, No. 3, 2004, pp. 145-154. doi: 10.1016/j. conbuildmat.2003.10.002

22. Robeyst, N., "Monitoring Setting and Microstructure Development in Fresh Concrete with the Ultrasonic Through-Transmission Method," $\mathrm{PhD}$ dissertation, Ghent University, Ghent, Belgium, 2010, $251 \mathrm{pp}$.

23. Robeyst, N.; Gruyaert, E.; Grosse, C. U.; and De Belie, N., "Monitoring the Setting of Concrete Containing Blast-Furnace Slag by Measuring the Ultrasonic p-wave Velocity," Cement and Concrete Research, V. 38, No. 10, 2008, pp. 1169-1176. doi: 10.1016/j.cemconres.2008.04.006

24. Voigt, T.; Grosse, C.; Sun, Z.; Shah, S. P.; and Reinhardt, H. W., "Comparison of Ultrasonic Wave Transmission and Reflection Measurements with P- and S-waves on Early Age Mortar and Concrete," Materials and Structures, V. 38, No. 282, 2005, pp. 729-738. doi: 10.1617/14267

25. NBN EN 196-3, "Methods Of Testing Cement—Part 3: Determination of Setting Times And Soundness," Bureau for Standardisation, Brussels, Belgium, 2005, 18 pp.

26. NBN EN 196-1, "Methods Of Testing Cement-Part 3: Determination of Strength," Bureau for Standardisation, Brussels, Belgium, 2005, $36 \mathrm{pp}$.

27. Robeyst, N.; De Schutter, G.; Grosse, C.; and De Belie, N., "Monitoring the Effect of Admixtures on Early-Age Concrete Behaviour by Ultrasonic, Calorimetric, Strength and Rheometer Measurements," Magazine of Concrete Research, V. 63, No. 10, 2011, pp. 707-721. doi: 10.1680/ macr.2011.63.10.707

28. Robeyst, N.; Grosse, C. U.; and De Belie, N., "Measuring the Change in Ultrasonic p-wave Energy Transmitted in Fresh Mortar with Additives to Monitor the Setting," Cement and Concrete Research, V. 39, No. 10, 2009, pp. 868-875. doi: 10.1016/j.cemconres.2009.06.016

29. Aitcin, P. C., and Neville, A. M., "How the Water-Cement Ratio Affects Concrete Strength," Concrete International, V. 25, No. 8, Aug. 2003, pp. 51-58. 
Reproduced with permission of the copyright owner. Further reproduction prohibited without permission. 